\title{
CRITÉRIOS DE DESENHO URBANO E AS INTERVENÇÕES DE INTEGRAÇÃO DE ARQUITETURA E URBANISMO COM A SEGURANÇA DAS CIDADES: Colômbia, Chile e Brasil.
}

\author{
Luciene Pessotti \\ Professora Adjunta do Departamento de Arquitetura e Urbanismo. \\ Centro de Artes, Universidade Federal do Espírito Santo. \\ luciene.pessotti@terra.com.br
}

\section{RESUMO}

Nas últimas décadas foram implementados na Colômbia e no Chile ações que objetivavam a integração do Desenho Urbano com a segurança pública. Os critérios de Desenho Urbano adotados foram os da teoria da Prevenção do Crime através do Design Ambiental (CPTED), cujas estratégias são ferramentas de planejamento dos espaços aplicadas para sua segurança. Objetiva-se abordar o tema da segurança cidadã e aproximar exemplos da realidade do Brasil com os países citados. No Brasil, os investimentos na redução da criminalidade se dá prioritariamente por meio da repressão policial, quando deveria combiná-los aos massivos investimentos no setor social - a verdadeira raiz do problema. A pesquisa de pós-doutoramento aborda o bairro de São Torquato, localizado no município de Vila Velha, Estado do Espírito Santo, Brasil. O bairro possui alto índice de violência. Desenvolveu-se para o local estudos de Desenho Urbano, com os critérios do CPTED, visando transformá-lo em um local mais seguro.

Palavras-chave: desenho urbano; segurança pública; segurança cidadã.

\section{RESUMO}

In the last decades, actions which aim at the integration of urban design with public security have been implemented in Colombia and Chile. The urban design guidelines adopted for this implementation were those of the Theory of Crime Prevention through Environmental Design (CPTED), which approach the use of space planning tools applied to crime control. The research explores the theme of citizen security and compares examples of the Brazilian to the Colombian and Chilean reality. In Brazil, investments in crime reduction are primarily made by means of police repression instead of massive investments in the social sector - the root of the problem. The postdoctoral research approaches São Torquato neighborhood, located in Vila Velha, State of Espírito Santo, Brazil. The neighborhood has a high rate of violence. Local urban studies have been developed, following the CPTED guidelines, with the purpose of making São Torquato neighborhood into a safer place.

Key words: urban design; public security; citizen security. 


\section{O MÉtOdo dA PREVEnÇÃo do CRIME ATRAVÉS do DESIGN AMBIENTAL (CPTED) NO CONTEXTO DA AMÉRICA LATINA}

$O$ presente artigo visa apresentar o resultado da pesquisa "O desenho urbano como instrumento na prevenção do crime", financiada pela Fundação de Amparo à Pesquisa e Inovação do Espírito Santo (FAPES), desenvolvida na Universidade Federal do Espírito Santo (UFES). O referencial teórico adotado foi o da Prevenção do Crime através do Design Ambiental (CPTED).

Apresentaremos os critérios de Desenho Urbano e as intervenções realizadas na Colômbia e no Chile, países que vêm demonstrando, nas ultimas décadas, a eficácia entre articulações do Desenho Urbano com segurança pública.

Do Brasil, apresenta-se as intervenções no Complexo do Alemão, Rio de Janeiro; e, a pesquisa com proposições de Desenho Urbano para o bairro de São Torquato, localizado no Espírito Santo, áreas com alto índice de violência e criminalidade.

Ressaltamos que no âmbito mundial algumas experiências são muito conhecidas e divulgadas como exemplos positivos de políticas de segurança pública a serem seguidas. Porém, diante da diferença observada em relação aos desafios da segurança cidadã nos países do hemisfério norte e sul (LIMA, 2013), e na tentativa de aproximar os exemplos da realidade do Brasil, optou-se por tratar de países da América Latina.

Os métodos de atuação da polícia nos países latinos para garantir a paz são dissuasórios, e não preveem a proposição e liderança de programas de transformação de Espaços Seguros. Nos países anglo-saxões, a polícia tradicionalmente atende as necessidades da população para garantir o bem estar, e eventualmente propõe iniciativas relacionadas às melhoras do espaço construído (LIMA, 2013).

No bojo das reflexões apresentadas objetiva-se conhecer o arcabouço institucional, áreas envolvidas, direcionamentos e ações possíveis. Não se objetiva elaborar ou criticar políticas. Almeja-se, a partir das políticas de segurança pública adotadas na Colômbia e no Chile para combater a insegurança e a criminalidade, compreender a justa medida que cabe ao urbanista nesse processo decisório tão complexo.

\subsection{0 método CPTED e suas estratégias}

O termo Crime Prevention Through Environmental Design (CPTED), originalmente formulado pelo criminologista C. Ray Jeffery na década de 1960, vem sendo estudado por arquitetos, urbanistas, jornalistas, antropólogos e pesquisadores da área de segurança pública como Jane Jacobs, Oscar Newman, Timothy Crowe e Roberson Bondaruk, que exploram em suas pesquisas a relação entre 0 ambiente construído e o comportamento criminoso.

A teoria do CPTED, afirma que os delitos ocorrem em determinados espaços devidos às oportunidades que o entorno físico oferece (SOUZA; COMPANS, 2009).

$\mathrm{Na}$ busca de aumentar a segurança nas cidades, observa-se a tendência de transformarem espaços públicos em espaços fechados, o que acaba dividindo a cidade em partes, dificultando a integração e a construção de um espaço urbano interligado.

A falta de integração afeta negativamente a relação da população com os espaços públicos da cidade, pois, são nas ruas, calçadas, parques e praças onde acontecem as relações interpessoais e as manifestações coletivas. Entretanto, essa relação diminui e a dinâmica do espaço urbano se altera, quando a sensação de insegurança aumenta. As pessoas buscam espaços fechados, como sinônimo de segurança, e os espaços públicos tornam-se inseguros, exatamente pelo uso reduzido, levando a um círculo vicioso entre abandono e multiplicação do medo e da insegurança.

Visando melhorar a percepção de insegurança e tornar os espaços públicos seguros, surgem teorias que entendem o espaço público como elemento de influência na segurança da população. A relação entre o desenho urbano e o modo que as pessoas utilizam e usufruem desse espaço são determinantes quando se trata de prevenção ao crime (LIMA, 2013). 
O CPTED tem como objetivo reduzir a incidência de crimes e melhorar a sensação de segurança da população, a partir de uma perspectiva baseada nas teorias da decisão racional, que estudam o processo de tomada de decisões de um potencial criminoso (HEIN; RAU, 2003). Considerando que existe três fatores favoráveis à uma atitude criminosa - um autor, um alvo acessível, e um espaço urbano com características ambientais propícias à atividade delitiva e ausência de vigilantes -, a metodologia apresenta estratégias que visam à alteração de variáveis situacionais, buscando reduzir as oportunidades através do aumento do esforço e da percepção de risco pelo criminoso (LIMA, 2011). Na prática, as quatro estratégias do CPTED constituem-se em diferentes aspectos de uma única metodologia que tratam da segurança no ambiente físico construído. São elas: (1) controle natural de acesso, que visa reduzir a oportunidade da prática de crimes nos espaços através da possibilidade de observação do acesso de pessoas desconhecidas; (2) vigilância natural, estratégia de prevenção que transmite ao delinquente a sensação de estar sendo observado; (3) reforço territorial, que se obtém com a ocupação dos espaços e com reforço da identidade através da formulação do desenho urbano e recuperação dos espaços de convivência com a participação da comunidade, e; (4) manutenção, que reduz a percepção de abandono e vulnerabilidade dos espaços urbanos, elimina a oportunidade e condição para a prática de delitos e é uma referência física de harmonia e controle social informal (SALLES 2007; TASCA, 2013; BONDARUK, 2007). Através dos estudos de caso veremos como os princípios do CPTED, aliado ao Desenho Urbano, alterou o usos e a segurança dos espaços públicos.

\section{O ESTUDO DE CASO DA COLÔMBIA E DO CHILE}

\subsection{Colômbia: Bogotá}

Bogotá, capital da Colômbia, é conhecida mundialmente por sua violência, mas, segundo Salles (2007), desde meados da década de 1990 uma reforma política e um conjunto de medidas vem mudando esse cenário. O Relatório Bogotá-Colômbia apresenta queda de mais de 50\% no número de homicídios por cada cem mil habitantes em Bogotá no ano 2000 (CARVALHO; CASTANHEIRA, 2001).

Vários programas e projetos multidisciplinares foram adotados visando a prevenção e a melhoria da convivência cidadã, e merece destaque a continuidade desses programas, que, mesmo com a troca dos governantes, se mantém. Acredita-se que esse é um dos pontos fortes do programa, fato que difere da realidade brasileira.

Listou-se as diretrizes e ações implementadas (CARVALHO, CASTANHEIRA, 2001; DIMENSTEIN, 2006c; BEDINELLI, 2007), com ênfase no âmbito do Planejamento Urbano, incluindo a implementação de equipamentos urbanos: (1) "Banco de Terras": a administração municipal comprou grandes terrenos para fazer o planejamento urbano adequado, impedindo que novas áreas se tornassem favelas; regularização dos bairros: doação de títulos de propriedade para moradores que não tinham as escrituras de seus terrenos; e oferecimento de casas em locais regularizados para os moradores de bairros que não poderiam ser urbanizados; (3) instalação de delegacias de família e defensorias públicas nos bairros; (4) instalação de bibliotecas, creches e escolas nos bairros pobres; (5) fornecimento de serviços básicos como energia, água potável e esgoto aos bairros pobres; (6) planejamento de intervenção nos espaços urbanos; (7) implementação de ações sociais de múltiplas frentes: reforma de espaços públicos e melhoria de escolas existentes, focando em programas de inserção dos jovens; (8) melhoria do transporte público nos bairros mais pobres: inserção de corredores de ônibus - TransMilênio (FIGURA 1) e ciclovias (FIGURA 2); nos finais de semana foram reservadas as principais vias para pedestres; além da inserção de imensos calçadões para pedestres; (9) implantação de uma gigantesca rede de bibliotecas, a Red Capital de Bibliotecas Públicas (BibloRed), que foi criada em 1998; (10) intervenção na recuperação de espaços críticos (segurança e convivência); (11) projetos urbanísticos para recuperação da região central de Bogotá, com criação e reforma de praças, atraindo mais pessoas para as ruas; (12) construção de parques em áreas deterioradas. 


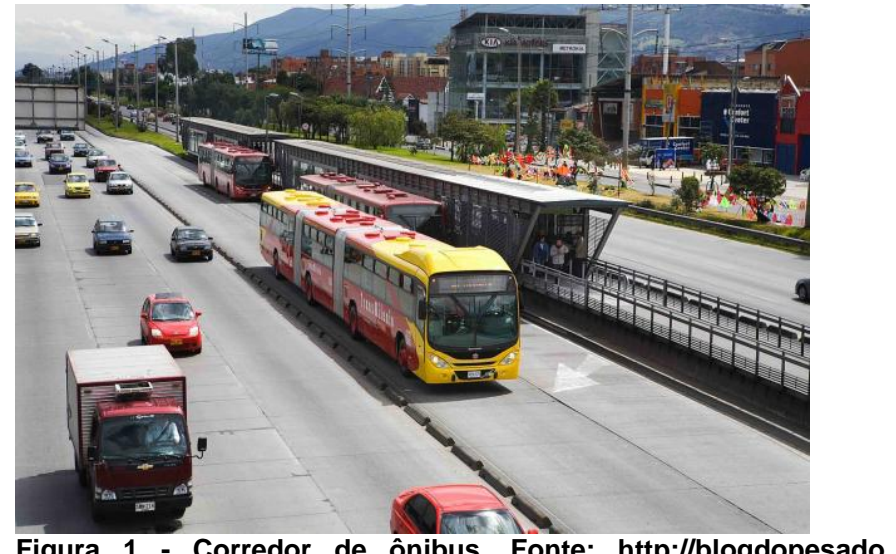

Figura 1 - Corredor de ônibus. Fonte: http://blogdopesado. blogspot.com.br/2012/08/volvo-vende-120-chassis-

biarticulados.html.

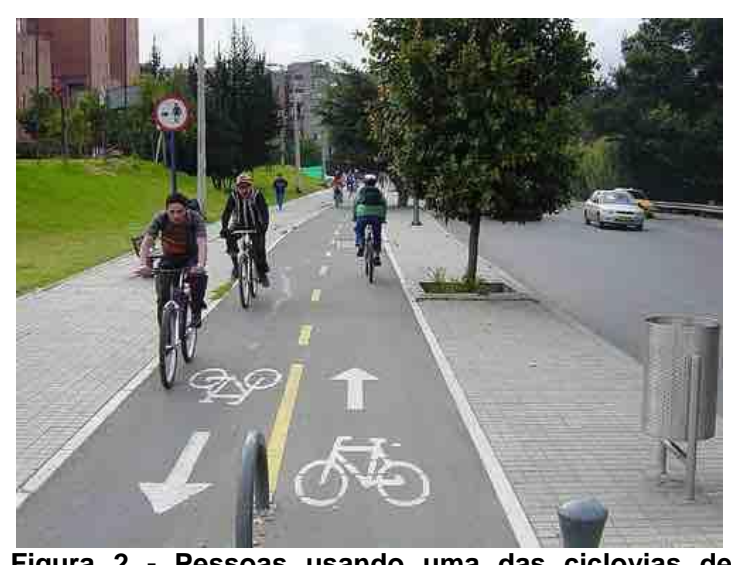

Figura 2 - Pessoas usando uma das ciclovias de Bogotá. Fonte: http://espiritooutdoor.com/cicloviasem-bogota-

uma-experiencia-que-deu-certo/

O maior exemplo dessa prática ocorreu no bairro El Cartucho, que era conhecido pela criminalidade, prostituição e tráfico de drogas, e o poder municipal o transformou no Parque Terceiro Milênio (FIGURA 3), inaugurado em 2002, encaminhando seus moradores para outros bairros. Atualmente o parque possui 16 hectares, encontrando-se em ampliação para 20 hectares, e representa uma importante ferramenta de lazer aos cidadãos (MORAR KALLAS, 2015).

Segundo o ex-prefeito de Bogotá, Antanas Mockus (SILVESTRE, 2006), responsável pela implementação das ações na cidade, os pontos cruciais para o sucesso deste plano são: (1) participação e fiscalização da comunidade; (2) unificação dos dados sobre homicídios e sua publicação mensal, independente do resultado; (3) permanência do Coordenador de Segurança da Prefeitura durante 12 anos, mesmo com a mudança de comando por conta das eleições, garantindo a continuidade do Programa.

Além dessas questões, é importante salientar as várias frentes de trabalho envolvidas: melhorias na educação, transporte, policiamento, e espaços públicos; alteração de legislação; regularização de terra.

É importante destacar que "profissionais de todas as áreas do conhecimento contribuíram para que a comunidade como um todo ganhasse em qualidade de vida" (SALLES, 2007, p. 54), e que, somente com a união dos diversos setores, apoio da população, e multidisciplinaridade do programa é possível reduzir os índices de criminalidade e obter resultados positivos.

\subsection{Medellín, Colômbia}

A cidade de Medellín foi premiada, em 2013, como a cidade mais inovadora do Mundo pelo Urban Land Institute, recebendo ainda o Prêmio Internacional de Desenho e Arquitetura (ISVIMED, 2014). Entretanto, na década de 1990 era conhecida como a "capital mundial da violência", tendo, em 1990, 380 homicídios para cada cem mil habitantes (MAISONNAVE, 2013; DIMENSTEIN, 2006d).

Visando reduzir os índices de criminalidade, os governos nacional, estadual e municipal se articularam e iniciaram um programa multidisciplinar, semelhante ao de Bogotá, com apoio do "setor privado, da academia, dos meios de comunicação e do setor social" (ISVIMED, 2014, p.20). Como resultado dessa nova política de segurança pública observou-se uma queda de quase $80 \%$ na taxa de homicídios entre 1991 e 2010, chegando a ter apenas 38 homicídios para cada cem mil habitantes no ano de 2013, uma taxa ainda elevada, mas substancialmente menor (MAISONNAVE, 2013; DIMENSTEIN, 2006d). Medellín, como Bogotá, mostrou que "a vacina para reduzir níveis de violência, mesmo em lugares pobres, já foi inventada e não depende de acabar a miséria" (DIMENSTEIN, 2006a).

Segundo Dimenstein (2006d), em geral foram adotadas medidas repressivas, preventivas e educacionais, além de "reformas urbanas nos bairros mais pobres, alguns deles nas montanhas, totalmente isolados", como: (1) construção de escadas; (2) coleta do lixo; (3) ampliação e construção de escolas; (4) abriram-se centros de saúde; (5) construção parques-biblioteca em áreas com indicadores de violência mais altos - promovendo convivência, cultura e lazer; (6) ofereceu-se sistema de transporte, instalando-se teleféricos, conhecidos como Metrocable (FIGURA 4), ligando morros de Medellín. 


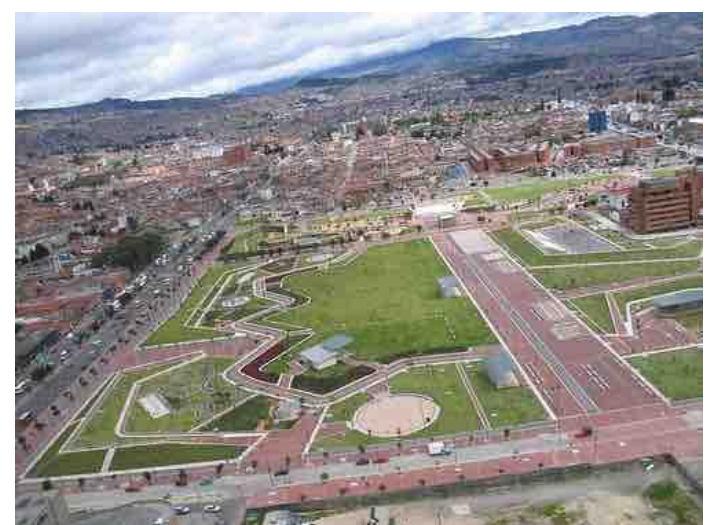

Figura 3 - Parque Novo Milênio. Fonte: http://violenciaurbanismo.blogspot.com.br/2010/06/parque-terceiro-mileniobogota.html

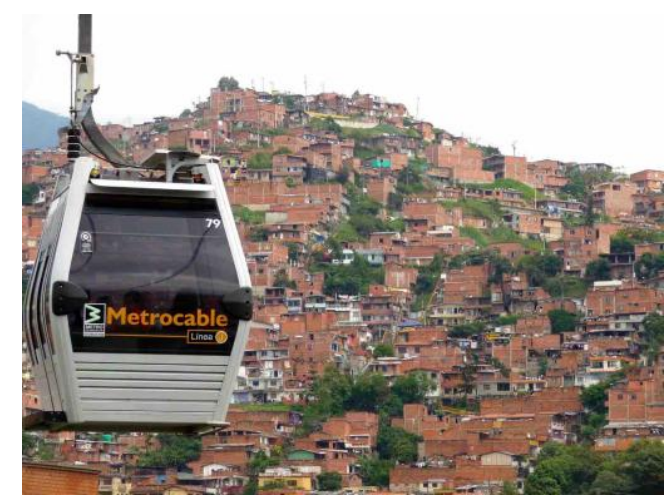

Figura 4 - Metrocable sobre a Comuna 13. Fonte: http://arquitecturaexpandida.org/blog/?p=298

Este tipo de transporte possibilita que serviços públicos e alternativas de vida sejam levados para locais onde o Estado simplesmente não conseguia chegar .

A Comuna 13 (FIGURAS 5 e 6), um aglomerado de 25 favelas nas montanhas que cercam Medellín, símbolo máximo do caos na cidade, merece destaque. Segundo Dimenstein (2006d), o poder público não atuava no local, e somente pessoas autorizadas podiam subir os morros. Nessa comuna a intervenção se deu em etapas (DIMENSTEIN, 2006d): destacando-se (1) a ocupação com bases militares; (2) assistência social; (3) denúncias de criminosos e diminuição da sensação de impunidade; (4) melhor treinamento dos policiais; (5) capacitação da comunidade sobre como lidar com a questão da segurança; (6) surgiram os "vigilantes do bairro" - voluntários que informam movimentos suspeitos às autoridades; (7) disseminaram-se os Mediadores de Conflito - pessoas de respeito no bairro aptos a intermediar disputas entre moradores, evitando confrontos físicos entre os mesmos; (8) diminuiu-se a resistência contra campanha do desarmamento; (9) jovens envolvidos na marginalidade foram convidados a trabalhar como educadores no espaço público - recebem um salário para manter a ordem na cidade; (10) a população ganhou autoestima, melhores perspectivas de vida, e passou a confiar mais no poder público do que nos grupos marginais que se disfarçavam dele.

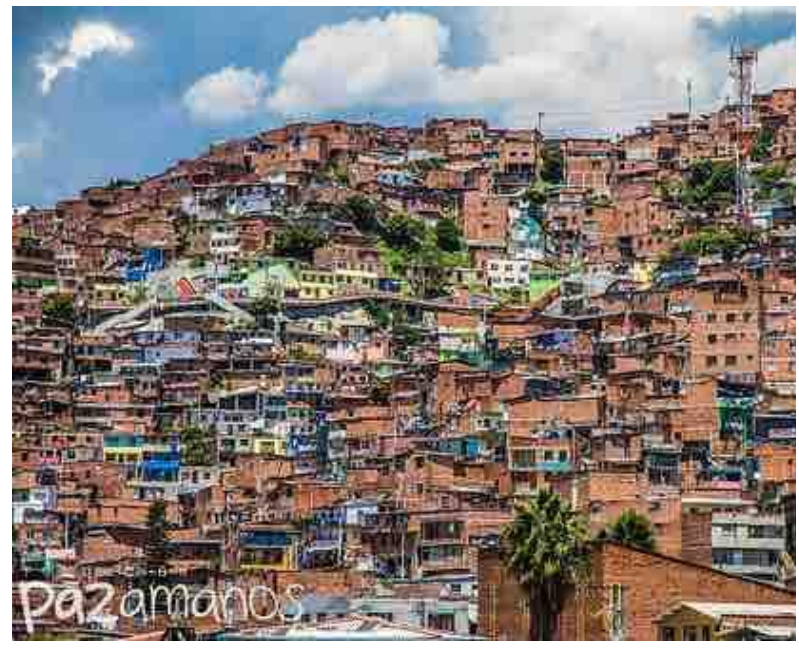

Figura 5 - Comuna San Javier - Comuna 13.

Fonte:

http://farm9.staticflickr.com/8091/8472000954_7404abce

1f.jpg

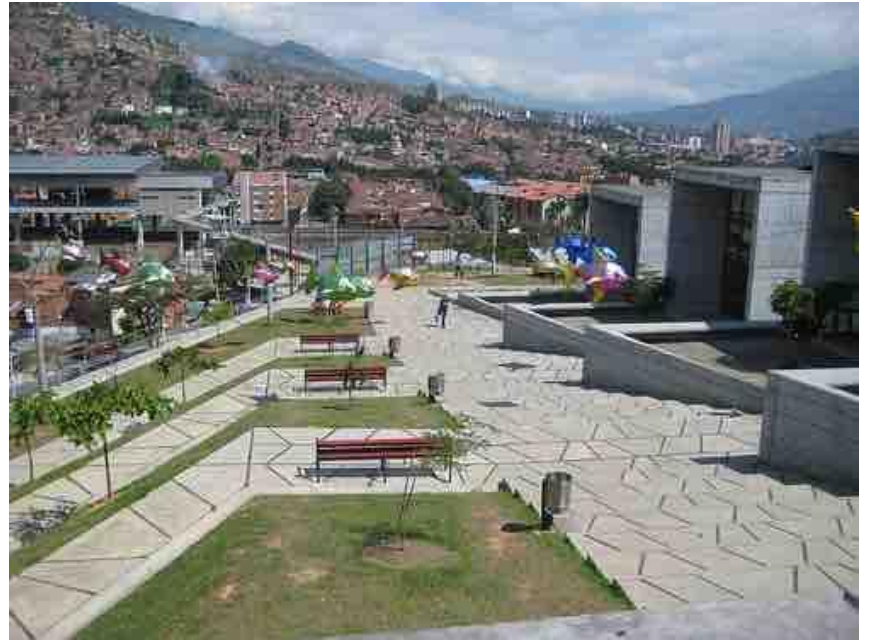

Figura 6: Parque Biblioteca San Javier - Comuna 13. Fonte: http://archinect.com/gsd-quilian/medellin-infrastructure-aschange

Segundo Aníbal Gaviria Correa (HAIDAR, 2013), prefeito de Medellín, o sucesso que a cidade vem obtendo em relação a diminuição da violência deve-se a uma combinação de ações, tais como, a autoridade, advinda da policia e da Justiça; o investimento social, e a intervenção em espaços públicos nos quais haja integração de atividades esportivas, culturais, em pontos de encontro comunitário. 
Para o prefeito, a queda de homicídios representa um fortalecimento da Justiça. Aníbal ainda destaca que a taxa de desemprego em Medellín é a mais baixa em vinte anos, e defende que emprego e educação reduzem a violência.

De forma geral, o avanço na redução da violência e criminalidade em Medellín ocorreu devido à combinação de três fatores: (COSTAS, 2008), (1) programa de Desmobilização de combatentes: paramilitares se entregaram em troca de reduções penais; (2) segurança Democrática: a pesada ofensiva militar contra guerrilheiros e paramilitares, promovida pelo governo, enfraqueceu e afastou dos centros urbanos muitos desses grupos, que antes dominavam grandes porções da Colômbia. "Em Medellín, a operação foi acompanhada, ainda, de um reaparelhamento e da renovação completa da polícia - iniciativa que visava a quebrar os laços de cooperação com grupos criminosos" (COSTAS, 2008); (3) projetos e intervenções sociais nos bairros pobres.

Dentre as intervenções urbanas destacam-se: (1) Metrocable: ao redor das estações foram erguidos postos de saúde, bibliotecas informatizadas, creches, instituições de ensino, centros de apoio ao pequeno empresário, e parques; (2) em outros pontos da periferia de Medellín foram construídas novas escolas, praças, e outros espaços públicos, como áreas de convivência, clubes sociais populares, e espaços de recreação e capacitação; (3) em pontos de encontro foram construídos espaços públicos que integram atividades esportivas e culturais.

Ressalta-se, portanto, que não é possível combater a criminalidade com ações ou medidas isoladas. Somente um planejamento detalhado, com ações conjuntas e multidisciplinares, pode ser eficaz na diminuição da violência de uma região com altos índices de criminalidade.

\subsection{Chile}

O Chile é considerado o país sul-americano pioneiro na utilização da metodologia CPTED. Segundo Lima (2013), os conceitos de "Arquitetura Contra o Crime" começaram a ser aplicados no Chile em 1985. Em 2001, com o Programa Comuna Segura adotou-se na cidade de Santiago a metodologia do CPTED como estratégia piloto.

Coordenado pelo Ministério do Interior, este programa visava a prevenção da violência e a diminuição da insegurança, abrangendo desde "questões estruturais, como a desigualdade socioterritorial ou o tráfico de entorpecentes, até a qualidade dos espaços públicos locais para melhora da qualidade de vida da população" (LIMA, 2013, p.15).

A ação seguinte foi a elaboração do Manual Espaços Urbanos Seguros, em 2004 (LIMA, 2013). Baseado nos critérios do CPTED, esse manual teve como objetivo apresentar "recomendações de desenho" e participação comunitária.

Em 2006 surge a Estratégia Nacional de Segurança Pública 2006-2010 (ENSP), que atuou "através de seis eixos de intervenção: institucionalidade, informação, prevenção, controle e sanção, reabilitação e reinserção social e assistência a vítimas" (DAMMERT, 2013, p.133).

Outros programas foram sendo implementados ao longo dos anos, até que em 2010 é lançado um novo programa, em substituição aos demais. Trata-se do Plano de Segurança Pública Chile Seguro 2010-2014, que contempla um conjunto de ações, que deveriam ocorrer entre os anos de 2010 e 2014, para combater a delinquência (CHILE, 2010a).

Esse novo programa tem como metas a redução do percentual de famílias vítimas de crimes e da quantidade de crimes no espaço público. Para atingir tais objetivos estabelece cinco áreas de intervenção ou eixos de ação. São eles (CHILE, 2010a, p.8): (1) prevenir - a prevenção social do delito: reduzir os fatores de risco que causam comportamento criminal e promover os fatores que protegem contra o envolvimento em atividades antissociais ou criminais, antes que elas aconteçam; (2) proteger: pode-se evitar os delitos através de políticas ou ações de prevenção ou proteção situacional, intervindo nas características do entorno onde ocorrem as situações ou circunstâncias facilitadoras; (3) sancionar: melhorar a eficácia do sistema penal, maximizando sua contribuição para a redução do crime; (4) apoiar: oferecer assistência às vítimas de crimes, causando a superação das consequências de vitimização, a prevenção da revitimização e a redução da vitimização secundária; (5) reabilitar: determinados tipos de 
programas, bem executados, diminuem a probabilidade de pessoas que cometeram um delito voltarem a fazê-lo.

O Programa tenta incentivar a participação dos cidadãos através de guias, acessíveis e disponíveis à toda a população, que ensinam medidas para reduzir o número de crimes em habitações, ruas e praças, e comportamentos pessoais que dificultam a ação do delinquente (CHILE, 2010b). Esses guias também funcionam como ferramentas de orientação técnica para arquitetos e urbanistas.

Os guias atualmente disponíveis são: (1) Guia Prevenção do Delito em Zonas Residenciais; (2) Prevenção de delitos no comércio: compilação e adaptação de experiências internacionais - Dezembro 2010; (3) Guia para a prevenção do roubo de veículos e acessórios; (4) Espaços Educativos Seguros: orientações técnicas de desenho de infraestrutura para a prevenção da violência escolar - Agosto 2013; (5) Cartilha: Espaços Educativos Seguros: orientações de Desenho Seguro para estabelecimentos educacionais existentes;

Além dessas questões ligadas ao CPTED, o guia oferece ainda medidas de autocuidado, e destaca a importância da vigilância natural, afirmando que a coordenação entre os vizinhos é a melhor forma destes se protegerem, incentivando o uso dos espaços públicos.

No ano de 2014 foram lançadas as metas do Plano Nacional de Segurança Pública e Prevenção da Violência e do Delito Segurança para Todos 2014-2018. O novo plano não aborda questões de Desenho Urbano, mas entende-se que as medidas anteriores e os guias disponibilizados à população e aos profissionais não devem ser ignorados, pois, introduziram orientações para o projeto de espaços da cidade, assim como, para as edificações.

\subsubsection{Santiago, La Granja, Vitacura e Peñalólen}

Conforme citado, no Chile a aplicação da metodologia do CPTED remonta o ano de 2000. Neste ano foi celebrado um convênio de colaboração entre o Munícipio de Toronto e a Fundación Paz Ciudadana (Chile), objetivando implementar de forma experimental o modelo em algumas comunas criticas, como La Granja e Peñalolén, onde os índices de vitimização chegavam a 14\% (RAU; PROSSER, 2009).

No ano de 2000, Granja e Peñalolén foram selecionadas como comunas piloto para se adaptar a metodologia CPTED, ambas localizadas na periferia de Santiago (RAU, 2005). O método foi aplicado também na comuna de Vitacura.

Em Peñalólen, as intervenções demonstraram uma redução na atuação dos traficantes de drogas. A experiência a partir de um espaço verde, no cruzamento de duas ruas principais, que encontrava-se coberto de vegetação, demonstrou depois de intervenções, que melhoraram a linha de visão, que os traficantes de drogas deixaram de utilizar o local. Com as mudanças espaciais as crianças e adultos assumiram sua utilização, atraindo vendedores e outros usuários, modificando o perfil de apropriação da área (STEPHENS, 2005, p.4).

Stephens (2005, p12), informa que as mulheres geralmente acompanham as crianças e transformam-se formadora de opinião sobre essa nova perspectiva do CPTED e da segurança pública, pois, onde estas se sintam seguras e estão ativamente envolvidos com seus ambientes, todos podem se sentir mais seguros, tanto a curto e longo prazo.

Em sua análise sobre o CPTED, Rau (2005), ao apresentar conceitos e estudos de caso no Chile, reforça a importância do reforço da apropriação territorial.

\subsubsection{Santiago}

No que tange ao Desenho Urbano, exemplificaremos os principais elementos morfológicos que foram adotados no espaço urbano e que influenciaram diretamente na melhoria da segurança de Santiago, tais como, os elementos urbanos. Os postes, lixeiras, bancos, mesas, pontos de ônibus, ponto de taxi, banca de jornal, banheiros e telefones públicos são exemplo. Sua disposição, quantidade e estado de conservação oferecem qualidade urbana, diminuindo a sensação de espaço abandonado, que aumenta a sensação de perigo e proporciona o crime (FIGURA 7). 
Segundo a estratégia do CPTED a vegetação/paisagismo pode ser uma forma de proteção para atividades antissociais, servir como ponto de lazer para os moradores locais e como atrativo para a presença de visitantes. Cabe destacar que a vegetação pode ser um aliado ou um vilão, pois árvores muito volumosas e que projetam sombras podem ser usadas por assaltantes para emboscar transeuntes (FIGURA 8).

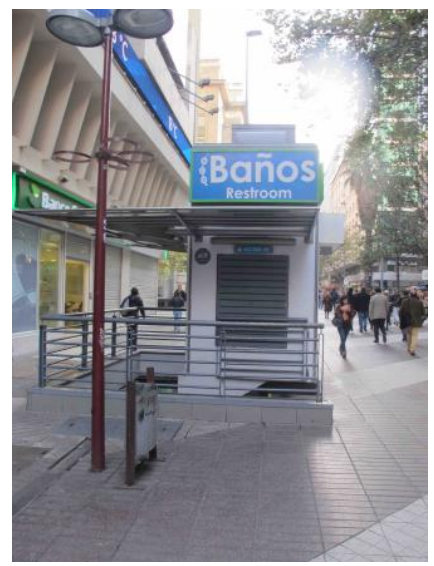

Figura 7: Banheiros públicos, Santiago, Chile. Fonte: Foto da autora (jun, 2016)

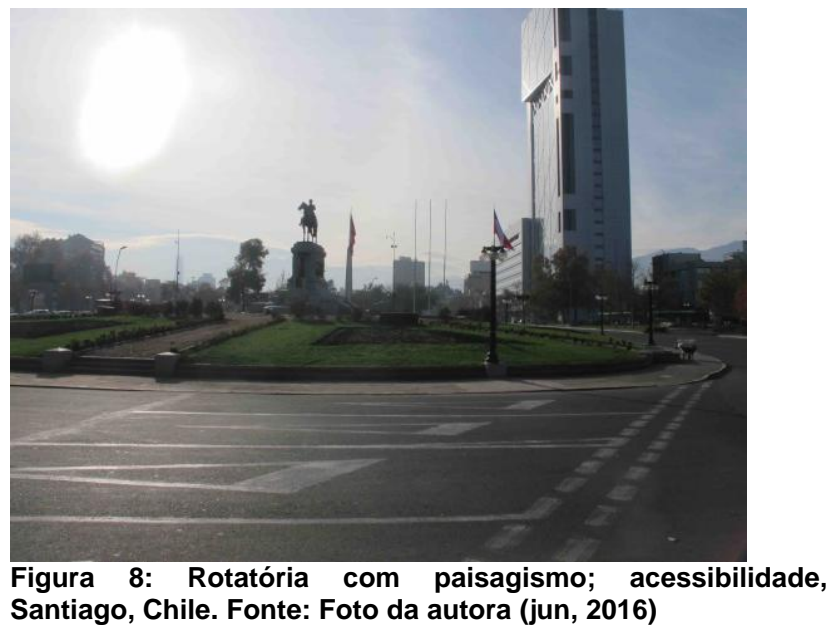

Santiago, Chile. Fonte: Foto da autora (jun, 2016)

Os equipamentos urbanos e lugares especiais na cidade influenciam na construção da paisagem urbana; o paisagismo; os acessos; o fluxo de veículos ciclistas e pedestres, notadamente, o sistema viário e sua relação com a travessia de pedestres nas ruas; infraestrutura de transporte; pavimentação; acessibilidade, proporcionam seu uso e favorecem, portanto, segurança aos usuários e a cidades (FIGURAS 9 e 10).

Além destes elementos morfológicos, citamos, também, a importância da mobilidade urbana. $O$ espaço urbano deve ser espaço movimentado, humanizado, vivenciado. Somente assim, com a diversidade, com a mobilidade, facilidade de acesso, poderão se produzir ambientes possivelmente seguros, considerando com absoluta certeza a importância de políticas sociais e públicas mais justas e igualitárias servindo como "cimento" social, político e econômico dessas intervenções físicas urbanas.

No que tange a Segurança Pública buscou-se alterar a dinâmica de usos e apropriação dos espaços urbanos evitando-se a multiplicação do medo e da insegurança. Assim, ações de Segurança Pública estimularam o cuidado e o uso dos espaços públicos (FIGURAS 11 e 12).

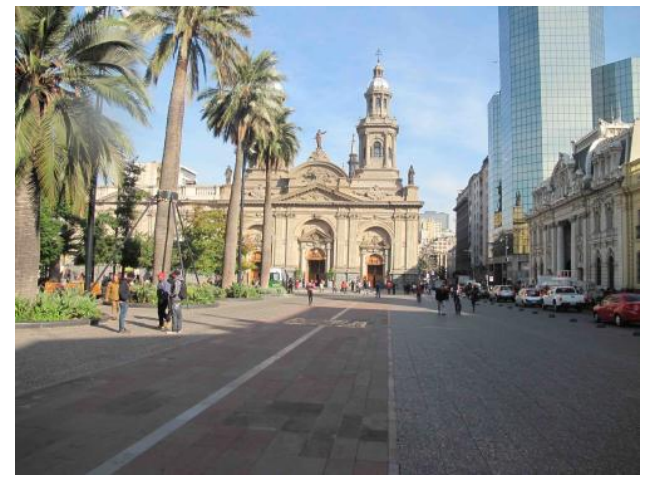

Figura 9: Integração de espaços públicos (praça, calçadas, vias) com monumentos, Santiago, Chile. Fonte: Foto da autora (jun, 2016)

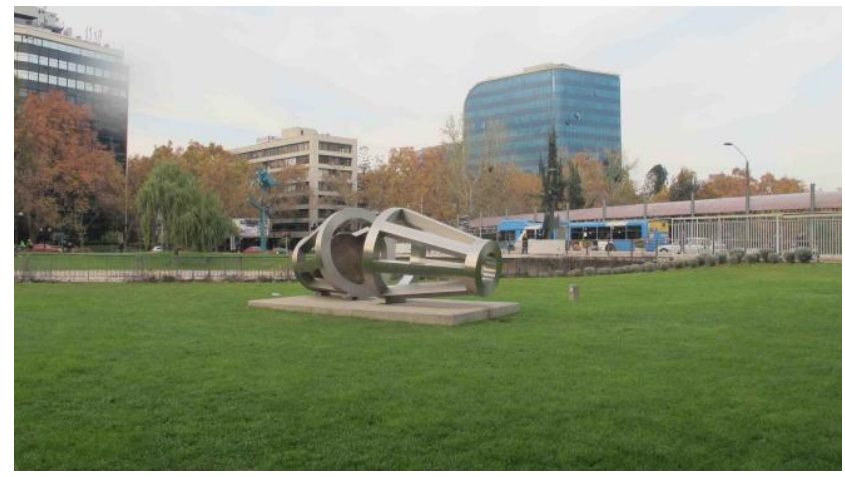

Figura 10: Espaços de arte no contexto urbano, Parque de las Esculturas. Santiago, Chile.

Fonte: Foto da autora (jun, 2016) 


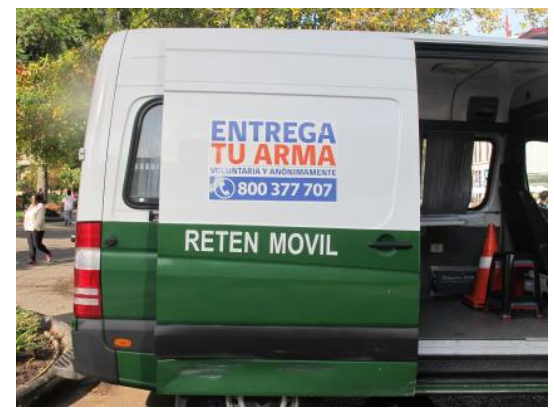

Figura 11 - Champanha de desarmamento com pontos móveis de coletas de armas. Santiago, Chile. Fonte: Foto da autora (jun, 2016)

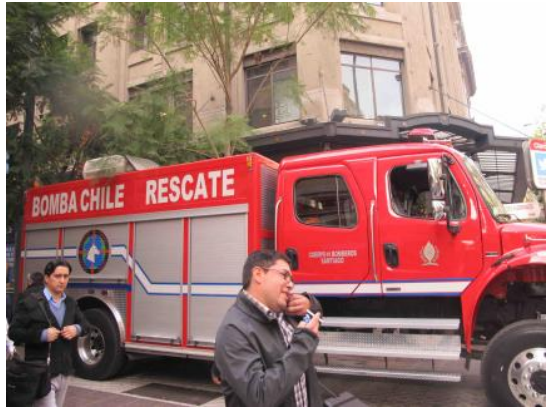

igura 12 - Ruas com vigilância e monitoramento constante. Santiago, Chile.

Fonte: Foto da autora (jun, 2016)

\subsubsection{Vitacura}

No ano de 2004 se aplicou a estratégia do CPTED na comuna de Vitacura, que possui uma situação econômica muito mais alta que os demais comunas.

Tratou-se segundo Rau (2005), de uma estratégia de marketing social. Os moradores do local foram apresentados ao método do CPTED e valorizou-se a estratégia de Janes Jacobs, proposta em Mortes e Vidas de Grandes Cidades (1961). Estimulou-se os moradores a serem como os olhos da rua, com a frase: "veámonos en Vitacura".

Se informou em placas distribuídas nos postos de eletricidade quais eram as boas e as más práticas ambientais em relação ao crime e sobre a percepção do medo. Como exemplo utilizou-se fotos da própria comuna. Seguem fotos de estratégias do CPTED (FIGURAS 13 e 14).

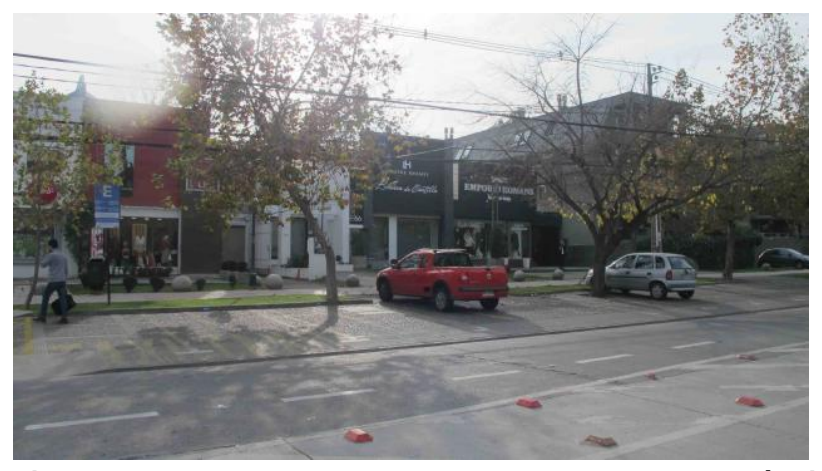

Figura 13 - Amplas calçadas com destaque para a ausência de muros para o fechamento dos lotes, favorecendo a visibilidade das edificações. Vitacura, Chile. Fonte: Foto da autora (jun, 2016)

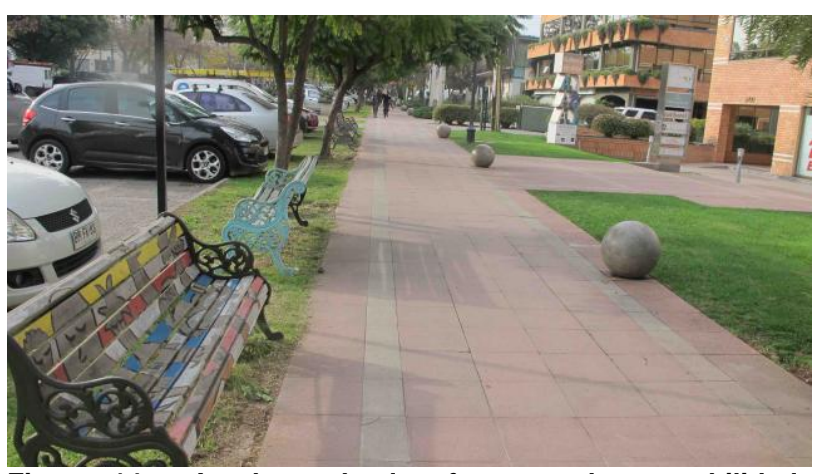

Figura 14 - Amplas calçadas favorecendo a mobilidade urbana; bancos e tratamento paisagístico. Vitacura, Chile. Fonte: Foto da autora (jun, 2016)

\subsubsection{Peñalolén e La Granja}

Segundo Rau (2005), as primeiras comunas escolhidas como lugares pilotos no Chile no ano de 2000 para aplicação do CPTED foram La Granja e Peñalolén, ambas localizadas na periferia de Santiago.

Após sistematização de dados sobre a criminalidade do local se aplicaram os conceitos do CPTED para se diagnosticar as áreas mais vulneráveis ao crime. Após esse diagnóstico se interviu nos espaços visando sua seguridade. As variáveis ambientais prioritárias detectadas nos diagnósticos foram: a existência de locais vazios, sem elementos urbanos, e com acúmulos de lixo.

Investiu-se na melhoria dos espaços públicos, colocação de luminárias e mobiliário urbano, recurso para atrair usuários e estes então passariam a atuar como vigilantes naturais do local.

Realizou-se uma campanha ambiental em colégios e outros setores organizados sobre a coleta do lixo.

Após a aplicação em 14 pontos de maior incidência de criminalidade foram obtidos resultados positivos e a experiência passou a ser adaptada a realidade local. 


\section{POLÍTICA PÚBLICA DE SEGURANÇA NO BRASIL E OS CRITÉRIOS DE DESENHO URBANO: O CASO DO COMPLEXO DO ALEMÃO (RJ) E DE SÃO TORQUATO (ES)}

\subsection{Morro do Alemão (RJ)}

Para abordar a importância de ações de Política Pública de Segurança no Brasil que relacionam-se com os critérios de intervenções urbanísticas é preciso contextualizar alguns dados.

Segundo dados do Censo de 2010 do Instituto Brasileiro de Geografia e Estatística (IBGE), o Brasil tinha, naquela ocasião, 11,42 milhões de pessoas morando em assentamentos irregulares, número que corresponde a $6 \%$ da população do país. Em vinte anos a proporção de brasileiros que moram nessas áreas, em condições precárias, quase dobrou.

Tal situação reflete a realidade histórica do planejamento das cidades no Brasil. Segundo Balbim et. al. (2013), houve no país uma incapacidade em ofertar terra para a população de baixa renda.

Nas favelas do Brasil há uma grande omissão na oferta de políticas de segurança pública, de serviços sociais básicos e equipamentos públicos. A ausência do Estado tem como consequência a formação e permanência de "ambientes onde a população está mais exposta a situações de risco e violência, reforçando a vulnerabilidade social de muitas famílias" (BALDIM et. al., 2013, p. 23).

Em 2007, foi criado pelo Ministério das Cidades (MCidades), o Programa de Aceleração do Crescimento (PAC). O PAC, estruturado no planejamento estratégico de médio e longo prazos, objetivava superar os gargalos de infraestrutura do país. O PAC 2, lançado em 2010, denominado Minha Casa Minha Vida, foi destinado a suprir o déficit habitacional. Este eixo inclui "as intervenções de urbanização de assentamentos precários, que contemplam ações de produção e melhorias habitacionais; água, esgoto, drenagem, viário e iluminação; saúde, educação, esporte, lazer e cultura; e regularização fundiária" (BALDIM et. al., 2003, p.7). Neste contexto é que em 2010 inicia-se o Projeto Estruturante - PAC Comunidade Complexo do Alemão - Urbanização na cidade do Rio de Janeiro, que é um dos maiores aglomerados de favela do país (FIGURA 15).

Segundo dados do Governo do Estado do Rio de Janeiro o Projeto Estruturante - PAC Comunidade Complexo do Alemão - Urbanização, foi desenvolvido em parceria com o Governo Federal, e integra o Plano Estratégico do Governo do Estado do Rio de Janeiro, tendo sido iniciado em 2008. O investimento do PAC entre 2008 e 2010, é da ordem de $R \$ 3,1$ bilhões.

O Complexo do Alemão é um bairro, formado por um conjunto de favelas, situado na Serra da Misericórdia, zona norte do município do Rio de Janeiro, e abrange uma área de 296 hectares (COUTO; RODRIGUES, 2015).

Segundo dados da Prefeitura Municipal do Rio de Janeiro o Complexo do Alemão é composto por quinze comunidades. A ocupação teria começado por volta de $1946 \mathrm{com}$ moradores nordestinos e imigrantes ocupando uma região que se transformou em polo industrial. Entre a década de 1950 e 1970 há um crescimento populacional. Nos anos 2000, o Complexo do Alemão era comandado pelo tráfico de drogas e pela milícia. Passou a ser considerado um dos bairros mais perigosos do Rio de Janeiro e o último colocado no Índice de Desenvolvimento Humano (IDH) da cidade (PRJ, s.d.).

Segundo dados do Censo 2010 (IBGE, 2010), moram no conjunto de favelas cerca de 70 mil habitantes. Segundo Couto e Rodrigues (2015, p.17), o Complexo do Alemão, "como um lugar da cidade do Rio de Janeiro, só adquiriu existência nominal, administrativa e simbólica, a partir de 1993, quando foi oficializado como bairro". Tal medida legal se deu pelo decreto de Lei 2055/93

No entanto, segundo Soares (2013, quando foi reconhecido como bairro, o Complexo do Alemão tinha demográfica de 302 habitantes por hectare, seis vezes superior à densidade média do município do Rio de Janeiro, de 49 habitantes por hectare. $O$ autor ressalta (SOARES, 2013), que dados do Censo das Favelas (2008/2009), realizado pelo Escritório de Gerenciamento de Projetos do Governo do Estado do Rio de Janeiro (EGP-Rio), estimam que população do Complexo do Alemão supere 85 mil pessoas. 
Em 2010 o Exército Nacional ocupou o território permanecendo por cerca de dois anos. A ocupação deu início ao estabelecimento das Unidades de Polícia Pacificadoras (UPPs). Segundo o Governo do Estado do Rio de Janeiro (2017), a Unidade de Polícia Pacificadora (UPP) é "um dos mais importantes programas de Segurança Pública realizado no Brasil nas últimas décadas". O programa, implantado pela Secretaria de Estado de Segurança do Rio de Janeiro, no fim de 2008, foi planejado e coordenado pela Subsecretaria de Planejamento e Integração Operacional. Os princípios que norteiam o programa são os da Polícia de Proximidade, "um conceito que vai além da polícia comunitária e tem sua estratégia fundamentada na parceria entre a população e as instituições da área de Segurança Pública".

O conceito das UPPs prevê a integração e parcerias entre os governos das três esferas e entre diferentes atores da sociedade civil organizada. Teve como objetivo principal a retomada permanente de comunidades dominadas pelo tráfico de drogas, e, propor a proximidade do Estado com a população das áreas contempladas pelo programa.

Segundo o Governo do Estado do Rio de Janeiro (2017), "a pacificação ainda tem um papel fundamental no desenvolvimento social e econômico das comunidades, pois, potencializa a entrada de serviços públicos, infraestrutura, projetos sociais, esportivos e culturais, investimentos privados e oportunidades".

Segundo dados do Governo do Estado do Rio de Janeiro (2017) foram ocupados na capital 264 territórios, e implantadas de 38 UPPs, com um efetivo atual de 9.543 policiais.

As intervenções que ocorreram no Conjunto de Favelas do Alemão integram o conjunto de ações iniciadas em 2007 pelo Governo Federal em áreas tradicionalmente marginalizadas pelo Estado, deficientes em infraestrutura. Através de diversas parcerias, no bojo do Programa de Aceleração do Crescimento (PAC), iniciaram-se intervenções urbanísticas, com a construção de diversos equipamentos urbanos, conjuntos habitacionais, instituições de ensino e de saúde.

O Governo Federal, juntamente com o Governo do Estado, e a Prefeitura do Rio de Janeiro seguiu parâmetros das políticas públicas da Colômbia no PAC Comunidade Complexo do Alemão. Ainda que o Plan de Ordenamiento Territorial de Bogotá, segundo Lozano (2008) tenha tido escala metropolitana, houve a regulamentação do espaço público e acarretou importantes mudanças sócio-espaciais significativas, principalmente, pelos novos usos urbanísticos que se implementou na cidade. Segundo a autora (LOZANO, 2008), os projetos de melhoramentos urbanísticos geraram grande impacto na cidade porque têm requerido profundas transformações na percepção e no uso do espaço público.

Sendo assim, pode-se afirmar que o conjunto de intervenções que foram realizadas na Comunidade Complexo do Alemão seguem princípios do plano executado em Bogotá, Colômbia, e provocou uma profunda relação e percepção do uso do espaço publico.

Entretanto, a maior referência do PAC Comunidade Complexo do Alemão são as intervenções ocorridas em Medellín, notadamente pela forma de ocupação (militar, inicialmente) por adotar o teleférico como meio de transporte de massa, solução pioneira em âmbito mundial, que objetivou integrar áreas urbanas, e a implantação de equipamentos públicos nas estações, entre outras ações similares.

O sistema de Teleféricos, com 152 gôndolas integra a Comunidade Complexo do Alemão com o próprio território, e com o restante da cidade. Assim como em Medellín, no Rio de Janeiro objetiva-se integrar o território segregado ao sistema de transporte de massa (metrôs e ônibus); no entorno das estações do sistema de teleféricos, foram implantados equipamentos urbanos, tais como, biblioteca e sala de leitura. Houve melhorias habitacionais para mais de 7 mil famílias com a construção de 920 novas unidades habitacionais (FIGURA 16). No que se refere a infraestrutura urbanística foram realizadas obras para implantação de esgoto sanitário, abastecimento de água, iluminação, pavimentação, recuperação ambiental, obras viárias, drenagem pluvial e contenção de encostas. Novos espaços comunitários e educacionais, tais como o Espaço Esportivo, o Centro de Geração de Renda e o Centro Integrado de Atenção à Saúde (CIAS), Colégio Estadual Jornalista Tim Lopes, Centro de Referência para a Juventude (CRJ).

As obras do Projeto Estruturante - PAC Comunidade Complexo do Alemão - Urbanização tiveram impacto na acessibilidade, nas condições de habitação, saúde, educação, esporte e lazer, cultura, trabalho e renda e assistência social de aproximadamente 120.000 pessoas. 
Segundo Soares (2013), as intervenções urbanísticas PAC Comunidade Complexo do Alemão produziu radical transformação na paisagem. Novos marcos na paisagem, de grande apelo imagético e força simbólica influenciaram na criação e percepção de novas imagens das favelas no Brasil, resignificando a imagem da cidade e também do país, projetando-os internacionalmente. De paisagens invisíveis (final do Século XIX); indesejáveis (inicio do Século XX); reconhecidas (década de 1930-1960); reprimidas (décadas de 1960-1980 - Ditadura Militar); possíveis (década de 1980 a 2000), as favelas se tornaram paisagem turística.

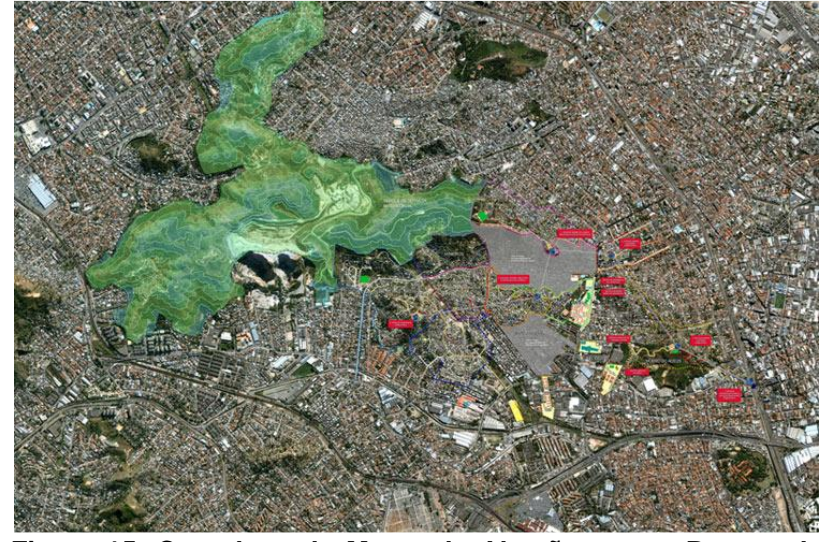

Figura 15: Complexo do Morro do Alemão com o Parque da Serra da Misericórdia. Fonte: (JÁUREGUI, s.d.)

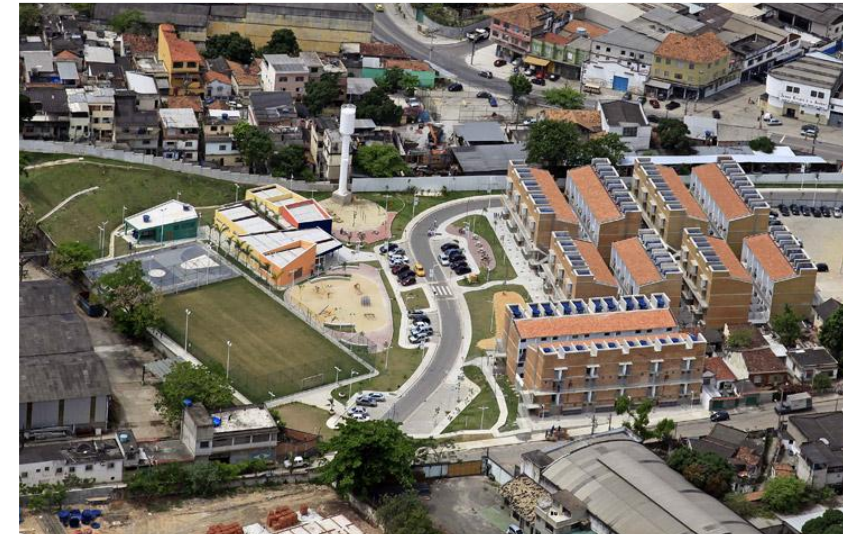

Figura 16: Novas unidades habitacionais construídas. Fonte: (JÁUREGUI, s.d.)

\subsection{São Torquato (ES)}

O bairro São Torquato situa-se no extremo norte do município de Vila Velha, parte integrante da Região Metropolitana da Grande Vitória (RMGV), pertencente ao Estado do Espírito Santo (FIGURA 17 e 18).

O bairro surge no final do século XIX devido a prosperidade do Porto de Vitória. As linhas de bonde, da década de 1910, e a construção da Ponte Florentino Avidos, que liga Vila Velha a Vitória (capital) em 1928, impulsionou o crescimento da região. A estação de trem inaugurada nas proximidades do bairro, que fazia a ligação da capital com o Sul do Estado, promoveu o intenso intercâmbio de São Torquato com o Rio de Janeiro. Com a evolução do funcionamento da Estrada de Ferro, a ocupação da região se intensificou (BAPTISTA, 2011).

Na década de 1960 se inicia a urbanização do bairro. Na década de 1970, em consequência da implantação de projetos industriais da Grande Vitória, se intensificou o processo de migração do interior para a Região Metropolitana. Esse fato fez com que atraísse comércio e, cada vez mais, novos moradores para a região, já que até então, era o local mais próximo dos postos de trabalho que se expandiam no Porto de Vitória (BAPTISTA, 2011). Entre os anos de 1950 e 1970 iniciou-se o uso misto, de residências e comércio, o que deu origem a um polo de comércio, existente até hoje. O uso do solo predominante no bairro é o residencial, embora, no entorno da principal praça exista um intenso uso de comércio e serviço. Com população com renda que varia de 3 a 4 salários mínimos, o local, possui índices de violência altos, e o espaço urbano é onde se dá a maior parte dos eventos criminosos.

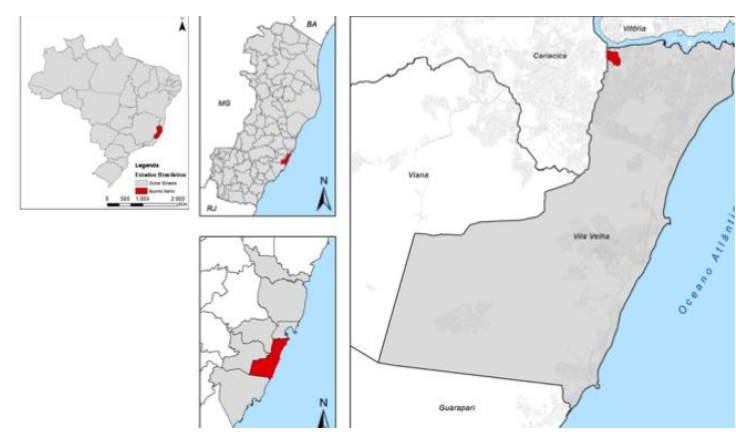

Figura 17 - Localização da área de estudo. Fonte: PESSOTTI (2016)

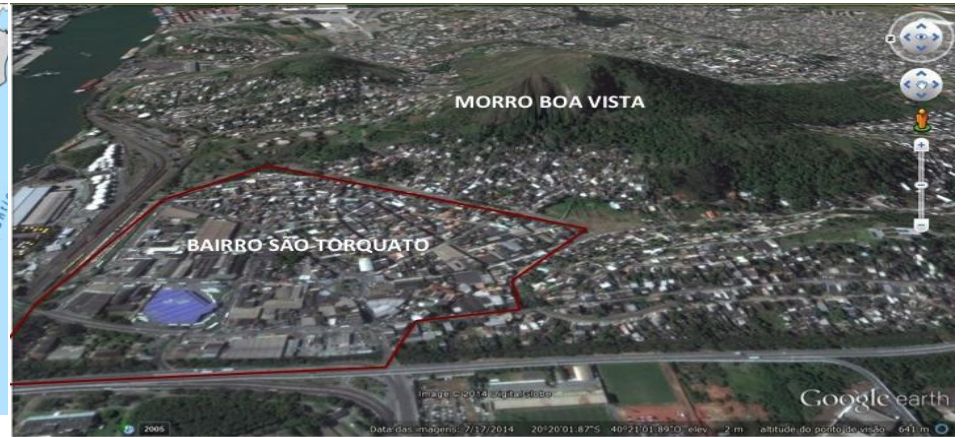

Figura 18 - Vista aérea da área de estudo. Fonte: PESSOTTI (2016) 


\subsubsection{Estudo / Análise do Crime}

Com base no documento cedido pela Secretaria de Estado da Segurança Pública e Defesa Social do Espírito Santo (2014), com informações de todas as ocorrências geradas no período de 2005 a 2014 no bairro São Torquato, foram extraídos e processados os dados de interesse para a pesquisa, como os grupos de crimes, tipo de local e ruas.

$\mathrm{Na}$ análise dos grupos de crimes, nota-se um elevado índice de crimes contra o patrimônio, que segundo o Código Penal (1940), classifica-se em furto, roubo ou extorsão (GRÁFICO 1).

No tipo de local, destacam-se os locais de comércio, residência e via pública. Observou-se a predominância de crime nas vias públicas, fato que reforça a necessidade de um Desenho Urbano que previna e iniba o crime (GRÁFICO 2).

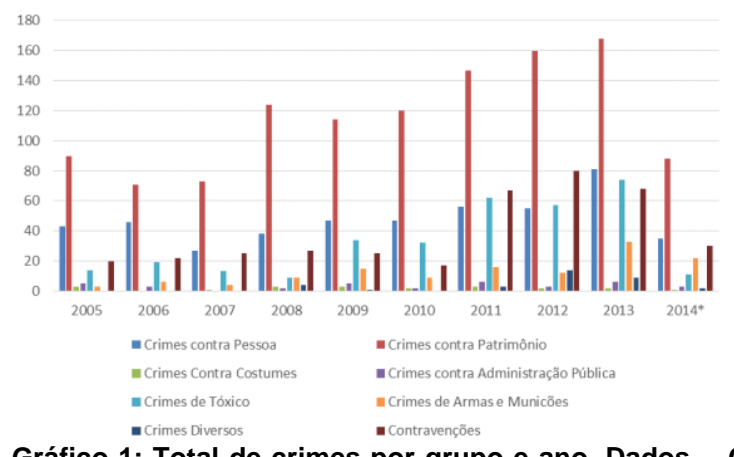

Gráfico 1: Total de crimes por grupo e ano. Dados da SESP, 2014. Fonte: Pessotti (2016)

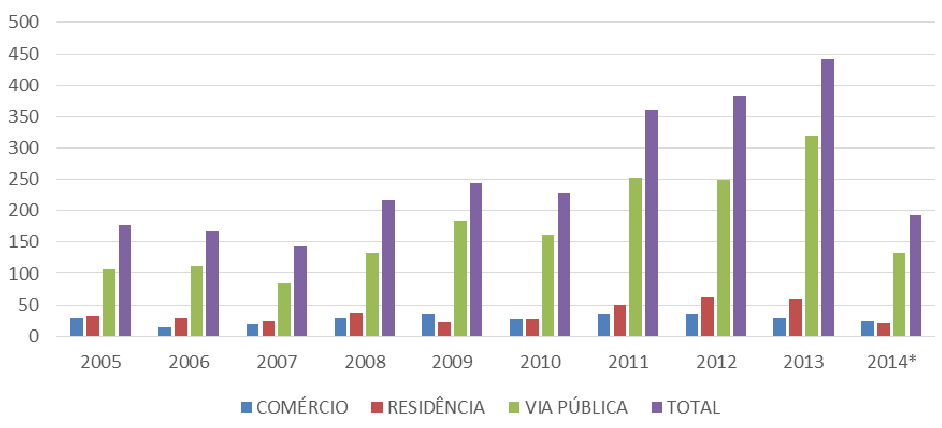

Gráfico 2: Total de crimes por tipo de local e ano. Dados da SESP, 2014. Fonte: Pessotti (2016)

\subsubsection{Mapas do Crime de São Torquato: Estudo de Caso}

Contatou-se pelos dados da criminalidade do bairro de São Torquato, que em sua maioria, os eventos compreendem aqueles contra o Patrimônio, contra Pessoa, Contravenções e Crimes de tóxico (SESP, 2014).

Pelas informações da Secretaria Estadual de Segurança Pública (SESP) (2014), no período analisado (entre 2005 e 2014), a grande maioria dos crimes e delitos ocorre nos espaços públicos.

Logo, chama a atenção, que nesse período, o maior número de crimes ocorreu em via pública, seguidos em residência e, por último, em comércio. Foram registrados 2.198 ocorrências (SESP, 2014). Ressalta-se, também, o aumento da criminalidade que envolvem jovens que atuam no tráfico de drogas, além, da apreensão de armas.

Nos Mapas do Crime realizados, observou-se que no período de 2005 a 2014 (até 31 de maio) todas as ruas do bairro tiveram ocorrências de crimes e delitos.

Os dados das ocorrências, espacializados de forma difusa, demonstram que em São Torquato a violência ocorre em toda a sua área. Conjectura-se, que apesar de existir no bairro uma Delegacia de Polícia, a ação de criminosos não é intimidada com a presença de uma equipamento de segurança pública.

Pode-se afirmar que o bairro de São Torquato insere-se num mesmo contexto de violência urbana de outros bairros e cidades de países pobres ou emergentes. O crescente fenômeno de diferenciação socioeconômica verificada no Brasil resulta, no município de Vila Velha, na separação de classes e na diferente valorização de áreas urbanas.

A marginalização espacial está presente em Vila Velha e observa-se que a população pobre mora nos bairros menos privilegiados, com carência de infraestrutura, equipamentos urbanos e investimento do Estado. São Torquato, pela sua localização geográfica, não pode ser considerado periferia, tendo em vista sua posição estratégica no tráfego de trânsito da região, e ao intenso comércio ali existente. Entretanto, tem em sua vizinhança imediata um enclave urbano, o Morro de Boa Vista, onde reside uma população de um menor poder aquisitivo e de maior carência de equipamentos e serviços urbanos. Mas, em termos econômicos o bairro pode ser considerado periferia, pois, uma grande maioria da população tem renda 
inferior a três salários mínimos. Embora os moradores de São Torquato não estejam segregados da dinâmica urbana do município, há no bairro, uma diferenciação com relação ao sentimento de segurança com relação a outros bairros da cidade. Por ter altos índices de violência, há no local, assim como em todas as cidades do país, um crescente e difuso sentimento de medo. Alguns locais e horários são evitados por todos. Logo, a apropriação dos espaços públicos fica comprometida.

No âmbito teórico podemos afirmar que nestes contextos dos países pobres há o fenômeno da fragmentação socioespacial (VASCONCELOS, 2013), e bairros como São Torquato e sua vizinhança imediata, são partes fragmentadas do tecido da cidade, onde o Estado tem uma atuação diferenciada em relação aos espaços mais valorizados.

No que tange aos elementos morfológicos do bairro, destacamos: (1) as ruas, com exceção das avenidas, são estreitas, e algumas se ligam a becos. O desenho das ruas não possui um traçado uniforme. As calçadas, em sua grande maioria, fora do padrão de acessibilidade universal, tem uma baixa qualidade para o trânsito de pedestres e permanência de moradores; (2) as edificações não possuem, em sua maioria, afastamentos frontais e laterais, prejudicando o campo visual e a vigilância natural. Constata-se baixa qualidade arquitetônica e até construtiva, trechos com poucas aberturas. Há, ainda, muitos trechos com muros cegos e pouca arborização nestes espaços. Essa característica, conforme preconiza o CPTED, cria uma ambiente hostil que influencia nas relações de vizinhança, aumentando a sensação de medo, não só de moradores, como de transeuntes; (3) em todas as vias a iluminação é considerada ineficiente, o que contribui para a criminalidade no bairro; (4) os elementos naturais, como arborização, paisagismo, etc., são escassos, há longos trechos áridos, sem vegetação, notadamente árvores. Verifica-se muitos elementos de vegetação mal posicionados em relação as ruas e calçadas estreitas. Outro fator agravante é a presença de lotes vazios e sem limpeza, o que facilita a permanência e atuação de meliantes. Logo, um dos grandes entraves para a redução da violência em São Torquato é a questão dos espaços públicos, dos espaços de vivência, de livre apropriação e a carência estrutural destes locais.

\subsubsection{Proposições de Desenho Urbano para São Torquato: as referências do CPTED para redução do crime}

Na UFES foram, inicialmente, realizados estudos integrados de Desenho Urbano, em nível de Estudo Preliminar, no âmbito da Disciplina de Urbanismo I e de Paisagismo I, associando as atividades de pesquisa e ensino. Conforme se atesta na FIGURA 19 e 20, o recorte projetual foi a Praça Getúlio Vargas e seu entorno, principal espaço público do bairro, subutilizado, e com grande incidência de crimes e delitos. $O$ objetivo, após realizados levantamentos e diagnósticos urbanísticos e paisagísticos, foi adotar os critérios do CPTED, visando melhorar a segurança do local, assim como, melhores condições urbanas, sociais e paisagísticas. Foram adotados os seguintes critérios: melhoria da mobilidade urbana; valorização dos espaços públicos; interligação dos equipamentos públicos; implantação de elementos urbanos; qualidade da iluminação pública; proposições que favoreçam a apropriação dos espaços públicos.

No âmbito da pesquisa, para se aplicar o CPTED utilizou-se os pressupostos teórico-metodológicos da Matriz SWOT - Strengths, Weakness, Opportunities, Threats vinculados ao Planejamento Estratégico.

Para todo o bairro de São Torquato realizaram-se análises, diagnósticos, identificaram-se problemas e potencialidades (com ênfase no âmbito social e urbanístico). A partir deste ponto definiram-se objetivos e diretrizes projetuais.

Após a análise dos problemas urbanos e sociais relacionados a violência e criminalidade, identificou-se as potencialidades existentes em São Torquato, correlacionando-os.

Inicialmente, assumiu-se os problemas como globais - que podem ser encontrados em outros locais do Brasil -, e desenvolveram-se diretrizes, que também pudessem ser genéricas, e consequentemente, aplicadas em outros locais com os mesmos problemas.

Por fim, definiram-se estratégias específicas para o bairro São Torquato com proposição de ações (FIGURAS 21 e 22).

No que tange o aspecto urbanístico há um enfoque nas estratégias do CPTED. Este item relaciona as diretrizes e estratégias desenvolvidas para o problema identificado com o que o CPTED preconiza, demonstrando a aplicabilidade do método no estudo de caso, considerando, também, intervenções 
paradigmáticas que são referências nacionais e internacionais de Desenho Urbano (FIGURAS 23 e 24).

O estudo de caso possibilitou a reflexão teórica, no contexto brasileiro, da possibilidade de se aplicar a metodologia de uma experiência internacional na proposição de soluções espaciais que reduzissem a criminalidade no espaço urbano, considerando as citadas intervenções da Colômbia e do Chile, pelas semelhanças do contexto socioeconômico.

O uso da metodologia do CPTED valorizou o principio da integração do desenvolvimento urbano à políticas de espaços seguros, com enfoque principal na revitalização dos espaços públicos.

A criminalidade, na maioria das regiões metropolitanas brasileiras, tem local e tipo bem delimitados, como a questão do tráfico de drogas, e demais crimes, que provocam isolamento, segregação socioterritorial e discriminações, e disseminam nos territórios relações de poder deturpadas, bem como, toda uma cultura de vivência socioespacial, ambas associadas ao crime.

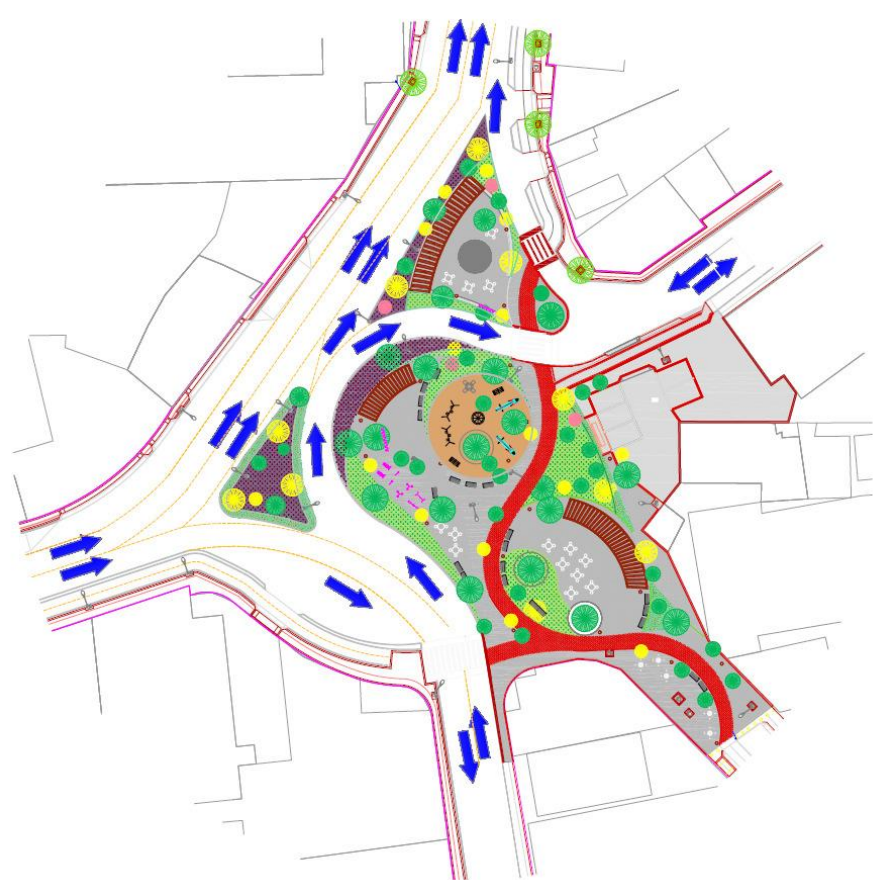

Figura 19 - Estudo Preliminar de Desenho Urbano, Praça Getúlio Vargas. Fonte: PESSOTTI (2016)

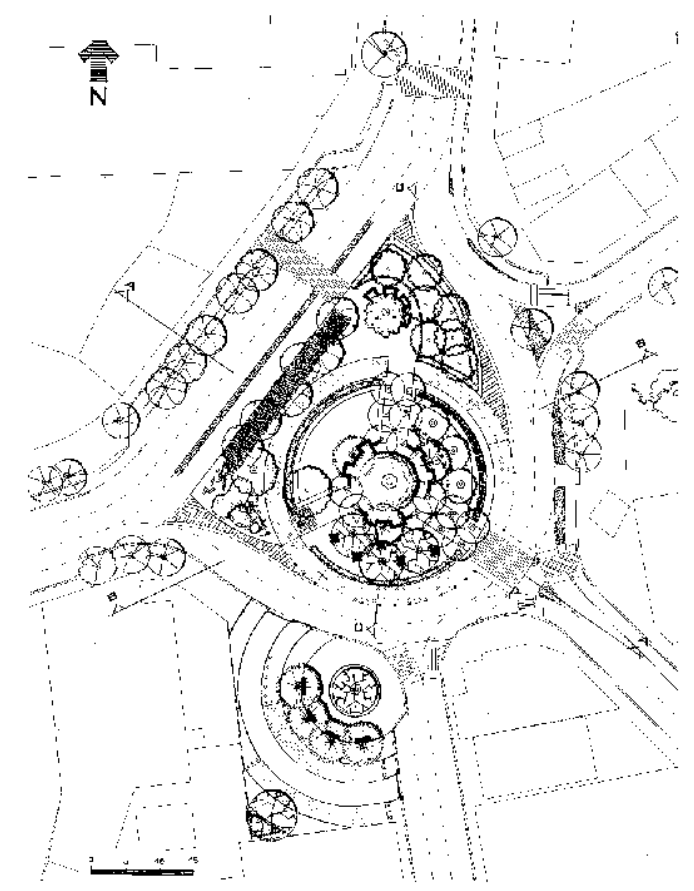

Figura 20 - Estudo Preliminar de Desenho Urbano, Praça Getúlio Vargas. Fonte: PESSOTTI (2016)

\begin{tabular}{|c|c|c|}
\hline PROBLEMA & POTENCIALIDADES & DIRETRIZES \\
\hline $\begin{array}{l}\text { Dificuldade de } \\
\text { moradores e } \\
\text { visitantes se } \\
\text { apropriarem } \\
\text { da praça } \\
\text { Getúlio } \\
\text { Vargas. }\end{array}$ & $\begin{array}{l}\text { - Intensa circulação de pessoas; } \\
\text { - Mínimo mobiliário urbano; } \\
\text { - Terminal de ônibus próximo à praça; } \\
\text { - Atividades econômicas, institucionais, } \\
\text { culturais e de lazer consolidadas no } \\
\text { entorno da praça; } \\
\text { - A praça é uma das principais } \\
\text { referências do bairro. }\end{array}$ & $\begin{array}{l}\text { - Possibilitar o encontro e permanência } \\
\text { - Dos moradores e visitantes nessa área; } \\
\text { econômicas, institucionais, culturais e } \\
\text { de lazer na praça e no seu entorno; } \\
\text { - Estimular o uso diversificado da praça } \\
\text { em diferentes dias e horários; } \\
\text { - Promover a inclusão social das pessoas } \\
\text { com deficiência. }\end{array}$ \\
\hline
\end{tabular}

Figura 21 - Tabela de Problemas, Potencialidades e Diretrizes no âmbito social. Fonte: PESSOTTI (2016)

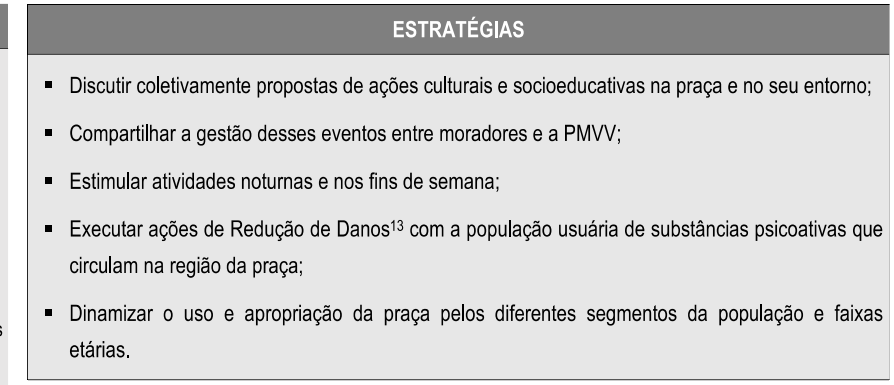

Figura 22 - Tabela com estratégias no âmbito social. Fonte: PESSOTTI (2016) 


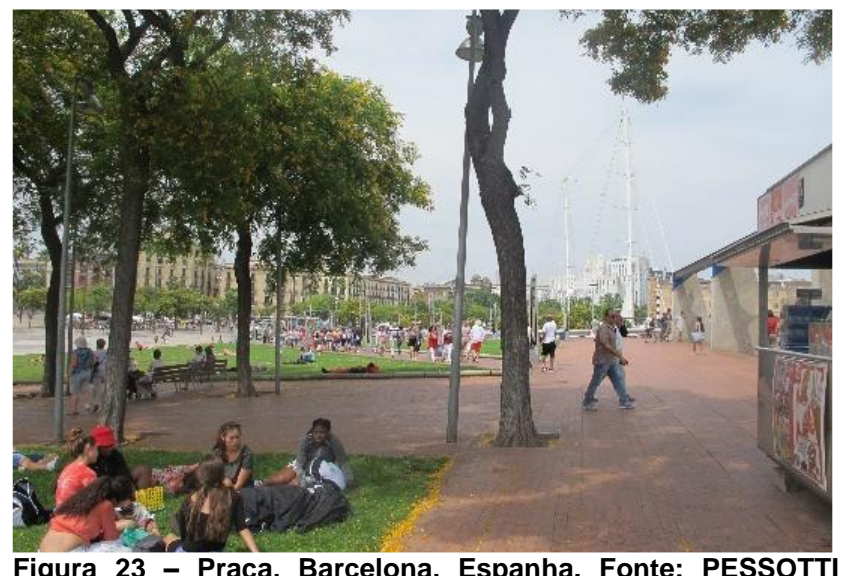

(2016)

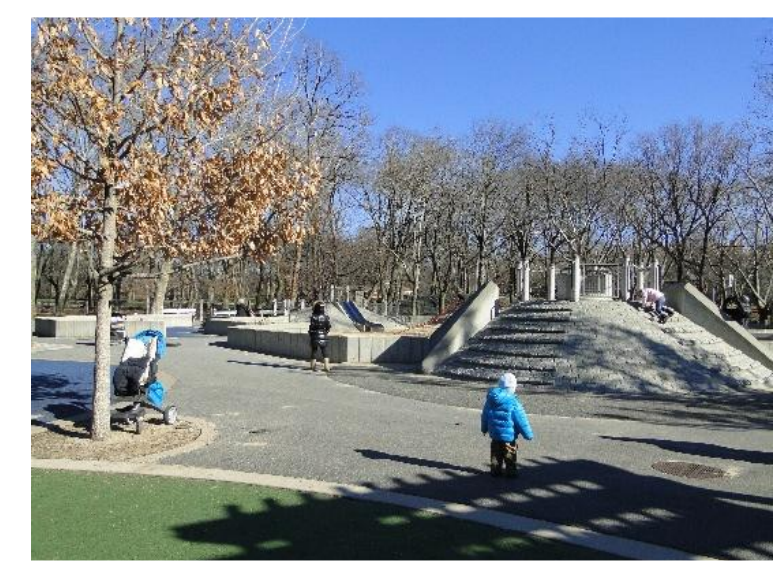

Figura 24 - Parquinho infantil no Central Park, Nova York. Fonte: PESSOTTI (2016)

\section{3 À guisa de conclusão: considerações teóricas sobre o método CPTED na América Latina}

Os critérios de Desenho Urbano adotados nas intervenções de integração de Arquitetura e Urbanismo com a segurança das cidades nos países da América Latina demonstram um esforço de se adaptar os pressupostos teóricos do CPTED em ambientes onde há graves problemas socioeconômicos, para melhorar a qualidade dos espaços públicos, e consequentemente, sua segurança,. Controle natural de acesso, vigilância natural, reforço territorial e manutenção: os critérios foram adotados para reverter quadros de violência com forte apelo da participação comunitária. Outros temas, como mobilidade urbana, que favorece a mobilidade social também foram objeto de intervenção.

Formulações de Desenho Urbano priorizaram a recuperação dos espaços de convivência, com o envolvimento da comunidade, objetivando o controle social informal e, por vezes, incorporando setores sociais nas ações do Estado.

Em alguns casos há a proposta de reaparelhamento e da renovação completa da polícia - iniciativa que visa romper laços de cooperação com grupos criminosos (COSTAS, 2008).

Há, também, questões de fundo mais profundas. Zygmunt Bauman, em Confiança e Medo na Cidade, enfatiza a nova fase histórica em que estão as cidades globais desde o fim do século XX. A cidade socialdemocrata está ameaçada em suas fundações por um fenômeno social: a verticalização crescente da diferenciação socioeconômica. Esse fenômeno reflete-se no espaço. Algumas áreas são valorizadas e outras são marginalizadas. Investimentos são polarizados nas áreas mais privilegiadas da cidades. A segurança é uma fator importante nesta análise. Há um grande e crescente sentimento difuso de medo nas cidades tornando-as fragmentadas. O sentimento de solidariedade foi substituído pelo sentimento de irmandade. A Modernidade sólida deu lugar a Modernidade líquida (BAUMAN, 2009).

O conceito de marginalização neste contexto é revisto por Vasconcelos (2013): no Brasil marginal é sinônimo de criminoso. A marginalização social também se estenderia a marginalização espacial.

Há ainda a questão conceitual das novas classes perigosas. Na contemporaneidade a exclusão se dá de forma permanente. O conceito de exclusão é considerado, por diferentes autores, como um processo de banimento de parte da sociedade de áreas valorizadas para áreas menos valorizadas, quais sejam, pobres, jovens, desempregados (VASCONCELOS, 2013).

Assim, observa-se que na América Latina, a adoção do CPTED, com seus critérios de Desenho Urbano, é associado as reflexões contemporânea da Sociologia e da Geografia Urbana, objetivando resolver, também, problemas sociopolíticos e econômicos.

No Brasil o CPTED foi utilizado como ferramenta para resolver os problemas de configuração e diferenciação socioespacial. A sociedade brasileira é "uma das mais desiguais do mundo, é um dos melhores exemplos das desigualdades entre áreas de grande afluência ao lado (ou distantes) de áreas de extrema pobreza" (VASCONCELOS, 2013). 
Pelos exemplos apresentados constata-se que a participação do Estado é fundamental nas questões socioespaciais: onde foi mais atuante, as diferenças e desigualdades são menores.

O método CPTED foi, portanto, utilizado pelo Estado nos países da América Latina como ferramenta para resolver os graves problemas da cidade socialdemocrata e, para enfrentar a violência em ambientes onde há piores situações de desigualdades no mundo.

O desenvolvimento de condições para que se possam (re)construir relações socioafetivas com o território, que respeitem e promovam a diversidade cultural, a sustentabilidade ambiental e socioeconômica, e estabeleçam patamares gradativamente expansivos de cidadania e autonomia para seus moradores é um caminho para resolver os problema da violência, da criminalidade e sua relação com o espaço.

É preciso reforçar vínculos existentes visando a construção de uma nova territorialidade.

É consenso, em nível planetário, a noção de sustentabilidade. O desenvolvimento urbano sustentável impõe o desafio de se redesenhar as cidades, com seus múltiplos territórios, de forma racional e inclusiva.

\section{BIBLIOGRAFÍA}

ABREU, Maurício de Almeida. (1994). Reconstruindo uma história esquecida: origem e expansão inicial das favelas do Rio de Janeiro. In: Espaço \& Debates, no 37, [p. 34-46].

BALBIM, Renato; KRAUSE, Cleandro; BECKER, Maria Fernanda; LIMA NETO, Vicente Correia; CASSIOLATO, Maria Martha; ANDRADE, Carla Coelho de. (2013). Metodologia de Avaliação de Resultados: O Caso das Intervenções do PAC urbanização de favelas. instituto de pesquisa Econômica Aplicada.- Brasília: Rio de Janeiro: Ipea, 1990- . Disponível em: < http://repositorio.ipea.gov.br/bitstream/11058/2342/1/TD_1903.pdf>. Acesso em 10 jan. 2017.

BAUMAN, Zygmunt. (2009). Confiança e medo na cidade. Rio de Janeiro: Zahar.

BAPTISTA, Jussara. (2011). Flores do pântano: histórias erguidas sobre o mangue de São Torquato. 1 ed. Vila Velha, ES. Ed. do Autor.

BEDINELLI, Talita. Bogotá inspira regularização de terra no RJ. Programa das Nações Unidas para o Desenvolvimento - PNUD, Rio de Janeiro, 19 jun. 2007. Disponível em: <http://gvces.com.br/bogotainspira-regularizacao-de-terra-no-rj?locale=pt-br>. Acesso em 14 mar. 2016.

BONDARUK, Roberson Luiz. (2007). A Prevenção do Crime Através do Desenho Urbano. Curitiba: Edição do autor.

CARVALHO, Nelson; CASTANHEIRA, Leila. Relatório Bogotá-Colômbia. (2001). As interpretações para a redução da criminalidade. Rio Estudos, Rio de Janeiro, no 39, p. 2-7, nov.

CHILE. Plan de Seguridad Pública 2010-2014. (2010a) Gobierno de Chile, Ministerio del Interior y Seguridad Pública. Chile.

CHILE. (2010b). Guía Prevención del Delito em zonas Residenciales. Gobierno de Chile, Ministerio del Interior y Seguridad Pública. Chile.

COSTAS, Roth. (2008). "PAC colombiano" resgata Medellín das mãos do tráfico e das milícias. O Estadão de São Paulo. 23 mar. Disponível em: <http://internacional.estadao.com.br/noticias/ geral,paccolombiano-resgata-medellin-das-maos-do-trafico-e-das-milicias,144459>. Acesso em 20 abr. 2015.

COUTO; Patricia Brandão; RODRIGUES, Ruth Imanishe. (2015). A gramática da moradia no Complexo do Alemão: história, documentos e narrativas. Instituto de Pesquisa Econômica Aplicada.- Brasília : Rio de Janeiro : Ipea 1990-. Disponível em: < http://repositorio.ipea.gov.br/bitstream/11058/6507/1/td_2159.pdf>. Acesso em 10 jan. 2017.

DAMMERT, Lucía. (2013). Chile: da narrativa à gestão efetiva. In: BASOMBRIO, Carlos (Ed.). Para aonde vamos? Análise de políticas públicas de segurança Cidadã na América Latina. São Paulo: Fórum Brasileiro de Segurança Pública, p.125-142.

DIMENSTEIN, Gilberto. (2006a). A vacina antiviolência. Folha de São Paulo. São Paulo, 15 out. 2006a. Disponível em: <http://www1.folha.uol.com.br/folha/dimenstein/colunas/gd161006.htm>. Acesso em 19 abr. 2015.

DIMENSTEIN, Gilberto. (2006b). Colômbia dá exemplo para reduzir violência. Folha de São Paulo. São Paulo, 16 out. Disponível em: <http://www1.folha.uol.com.br/folha/dimenstein/colunas/ gd161006e.htm>. Acesso em 19 abr.

DIMENSTEIN, Gilberto. (2006c). Bogotá combinou repressão com urbanismo e educação. Folha de São Paulo, 16 out. Disponível em: <http://www1.folha.uol.com.br/folha/dimenstein/colunas/ gd161006c.htm>. Acesso em 19 abr. 2015. 
DIMENSTEIN, Gilberto. (2006d). Medellín passou de capital da violência a laboratório da paz. Folha de São Paulo, 16 out. Disponível em: <http://www1.folha.uol.com.br/fsp/cotidian/ff1510200605.htm>. Acesso em 20 abr. 2015.

HAIDAR, Daniel. (2013). As lições de Medellín para as UPPs. VEJA. 29 dez. Disponível em: <http://veja. abril.com.br/noticia/brasil/as-licoes-de-medelin-para-as-upps/>. Acesso em 20 abr. 2015.

HEIN, Andreas; RAU, Macarena. (2003). Estudio comparado de políticas de prevención del crimen mediante el diseño ambiental CPTED. [S.I.]: Fundación Paz Ciudadana, Disponível em:

$<$ http://www.cejamericas.org/index.php/biblioteca/biblioteca-virtual/doc_view/734-estudio-compar adode-pol\%C3\%ADticas-de-prevención-del-crimen-mediante-el-diseño-ambiental-cpted.html>. Acesso em 05 jul. 2015.

INSTITUTO BRASILEIRO DE GEOGRAFIA E ESTATÍ́STICA (IBGE). (2010). Sinopse por setores. Censo 2010. Disponível em: <www.censo2010.ibge.gov.br/sinopseporsetores/?nivel=st>. Acesso em abril de 2016.

ISVIMED - Instituto Social de Vivienda y Habitat, Alcadia de Medellín. (2014). Carta de Medellin: sobre o porvir humano das urbes do mundo. Sétimo Fórum Urbano Mundial ONU-Habitat. Editora: Litotipo, Medellín, abr.

JÁUREGUI, Jorge Mario. (s.d.) Projeto de articulação sócio-espacial - Complexo do Alemão (Escala Territorial). PAC-UAP - Programa de Aceleração do Crescimento / Urbanização de Assentamentos Precários. Disponível em: < http://www.jauregui.arq.br/favelas_alemao.html>. Acesso em 10 jan. 2017.

LIMA, Renato Sérgio de (Coord.). (2013). Nova Técnica - Estudo Conceitual sobre os Espaços Urbanos Seguros. Fórum Brasileiro de Segurança Pública. São Paulo.

LIMA, Vera Cristina de Sousa. (2011). Espaço e criminalidade em favelas de Belo Horizonte. In: Anais... XIV Encontro Nacional da ANPUR, vol. 14, n. 1, maio. Disponível em: <http://unuhospedagem. com.br/revista/rbeur/index.php/anais/article/view/3651/3576>. Acesso em 3 set. 2014.

LOZANO, Lina Patrícia Giraldo. (2008). A mundialização do Espaço Urbano: O caso do centro antigo de Bogotá. Dissertação (Mestrado) - Departamento de Geografia da Faculdade de Filosofia, Letras e Ciências Humanas, Universidade de São Paulo, 2008.

MAISONNAVE, Fabiano. (2013). Luta antidrogas tem de mudar, diz prefeito. Folha de São Paulo, 02 dez. Disponível em: <http://www1.folha.uol.com.br/fsp/mundo/141745-luta-antidrogas-tem-de- mudar-dizprefeito.shtml\#_=_>. Acesso em 20 abr. 2015.

MORAR KALLAS. (2015). A renovação urbanística e social de Medellín. Disponível em: http://morarkallas.com.br/index.php/2013/10/a-renovacao-urbanistica-e-social-de-medellin/. Acesso em 10 abr. 2015.

NETO, Francisco Gelinski; SILVA, Jediael Emanoel Pereira da. A Prevenção e o controle da violência e criminalidade: programas exitosos. (2012). In: Anais... VI Encontro de Economia Catarinense. Tema 7 Economia Social e Políticas Públicas. Joinville, Santa Catarina. Disponível em: $<$ http://www.apec.unesc.net/VI_EEC/sessoes_tematicas/Tema7-Economia\%20Social\%20e\%20 Politicas\%20Publicas/Artigo-16-Autoria.pdf>. Acesso em 16 mar. 2016.

PESSOTTI, Luciene. (2016). O desenho urbano como instrumento na prevenção do crime. Relatório de Pesquisa - Fundação de Amparo à Pesquisa e Inovação do Espírito Santo (FAPES) - Departamento de Arquitetura e Urbanismo (DAU), Universidade Federal do Espírito Santo, Vitória.

PREFEITURA DO RIO DE JANEIRO (PRJ) (s.d.). Rio + Social. Territórios: Complexo do Alemão. Disponível em: < http://www.riomaissocial.org/territorios/complexo-do-alemao/>. Acesso em 16 jan. 2017.

RAU, M (2005). Prevención de la violencia y el delito mediante el diseño ambiental en Latinoamérica y El Caribe: Estrategias urbanas de cohesión social e integración ciudadana. In: DAMMERT, Lucía; PAULSEN, Gustavo. Ciudad y seguridad en América Latina. Santiago, FLACSO, p.85-105.

RAU, Macarena; PROSSER, Paola. Estudio de Evaluacion de Impacto de Estrategias en Cpted y Prevencion Situacional. Chile, Santiago, 2009. Disponível em: http://www.leemira.cl/biblioteca/download.php?id=72. Acessado em 03 de junho de 2015

SALLES, S.V. Adriana. (2007). Diretrizes para o espaço urbano público inibidor de delitos: Estudo de caso. 2007. Dissertação (Mestrado em Arquitetura e Urbanismo) - Programa de Pesquisa e Pós- Graduação da Faculdade de Arquitetura e Urbanismo. Universidade de Brasília, Brasília. Disponível em: <http://repositorio.unb.br/bitstream/10482/1126/1/Disserta\%C3\%A7\%C3\%A3o_ 2007 AdrianaVasconcellosSalles.pdf>. Acesso em 16 mar. 2016.

SESP - Secretaria de Estado da Segurança Pública e Defesa Social do Espírito Santo. (2014). Dados da Polícia Civil do Espírito Santo - Bairro São Torquato (planilha do Excel). Espírito Santo.

SILVESTRE, João. Experiência de Bogotá é apresentada na Assembleia Legislativa. (2006). Agência de Notícias ALRS, set. Disponível em: <http://www2.al.rs.gov.br/noticias/ExibeNoticia/ tabid/5374/Default.aspx?IdMateria=157795>. Acesso em 20 abr. 2015. 
SOARES, Adriano S.(2013). A paisagem como objeto de politicas publicas. O caso das favelas cariocas. Revista Geonorte, Edição Especial 3. vol. 7, n. 1, p. 15- 39 (ISSN - 2237-1419).

SOUZA, Maria J. N.; COMPANS, Rose. (2009). Espaços urbanos seguros: a temática de segurança no desenho da cidade. Revista Brasileira de Estudos Urbanos e Regionais, vol. 11, n. 1, p. 09- 24, mai. Disponível em: <http://unuhospedagem.com.br/revista/rbeur/index.php/rbeur/ article/viewFile/207/191>. Acesso em 31 maio 2015.

STEPHENS, Robert. Children, Playspace and CPTED. Paper of the 10th ICA Conference in Santiago (Chili). Santiago, Chile, 2005. Disponível em: http://www.veilig-ontwerp-beheer.nl/publicaties/childrenplayspace-and-cpted/view. Acessado em 03 de junho de 2015.

TASCA, Jorge Eduardo. (2013). A contribuição da avaliação de desempenho, como um instrumento de apoio à decisão, para a prevenção ao crime baseada no ambiente. Tese (Doutorado) - Programa de Pós-Graduação em Engenharia de Produção, Universidade Federal de Santa Catarina, Florianópolis, 2013.

VASCONCELOS, Pedro de Almeida. (2013). Contribuição para o debate sobre processos e formas socioespaciais nas cidades. In: A cidade contemporânea: segregação espacial. VASCONCELOS, Pedro de Almeida; Corrêa, Roberto Lobato; PINTAUDI, Silvana Maria (orgs.). São Paulo: Contexto.

http://www.rj.gov.br/web/informacaopublica/exibeconteudo?article-id=1036873

VASQUES, Leandro. (2013). Criminalidade não se combate só com repressão policial. Blog O Povo: informação sem preconceito. 23 mai. Disponível em: $<$ http://blog.opovo.com.br/blogdoeliomar/criminalidade-nao-se-combate-so-com-repressao- policial/>. Acesso em 20 abr. 2015.

VELÁSQUEZ, Hugo Acero. (2006). Os governos locais e a Segurança Cidadã. PNUD. Disponível em: $<$ https://www.researchgate.net/publication/268301627_OS_GOVERNOS_LOCAIS_E_A_SEGUR ANCA_CIDADA>. Acesso em 21 mar. 2016. 